\title{
Current Opinion on the Role of Neurogenesis in the Therapeutic Strategies for Alzheimer Disease, Parkinson Disease, and Ischemic Stroke; Considering Neuronal Voiding Function
}

\author{
Myung-Hoon Han ${ }^{1}$, Eun-Hye Lee ${ }^{2}$, Seong-Ho Koh ${ }^{2,3}$ \\ ${ }^{1}$ Department of Neurosurgery, Hanyang University Guri Hospital, Guri, Korea \\ ${ }^{2}$ Department of Neurology, Hanyang University College of Medicine, Seoul, Korea \\ ${ }^{3}$ Department of Translational Medicine, Hanyang University Graduate School of Biomedical Science \& Engineering, Seoul, Korea
}

Neurological diseases such as Alzheimer, Parkinson, and ischemic stroke have increased in occurrence and become important health issues throughout the world. There is currently no effective therapeutic strategy for addressing neurological deficits after the development of these major neurological disorders. In recent years, it has become accepted that adult neural stem cells located in the subventricular and subgranular zones have the ability to proliferate and differentiate in order to replace lost or damaged neural cells. There have been many limitations in the clinical application of both endogenous and exogenous neurogenesis for neurological disorders. However, many studies have investigated novel mechanisms in neurogenesis and have shown that these limitations can potentially be overcome with appropriate stimulation and various approaches. We will review concepts related to possible therapeutic strategies focused on the perspective of neurogenesis for the treatment of patients diagnosed with Alzheimer disease, Parkinson disease, and ischemic stroke based on current reports.

Keywords: Alzheimer Disease; Parkinson Disease; Stroke; Neurogenesis; Neural Stem Cells

- Grant/Fund Support: This work was supported by the Basic Science Research Program through the National Research Foundation of Korea (NRF) funded by the Ministry of Science, ICT and Future Planning (2015R1A2A2A04004865).

- Conflict of Interest: No potential conflict of interest relevant to this article was reported.

\section{INTRODUCTION}

As the aging population increases, common neurological disorders including Alzheimer disease (AD), Parkinson disease (PD), and ischemic stroke (IS) have increased and become important health issues with increasing socioeconomic burdens throughout the world [1].

The clinical characteristics of $\mathrm{AD}$ are related to progressive memory loss and cognitive deterioration. The neuropathological traits of $\mathrm{AD}$ are massive neuronal death with senile plaques, which are formed by the aggregation of amyloid- $\beta(A \beta)$ peptides, and neurofibrillary tangles, which form from abnormal hyperphosphorylation of cytoskeletal tau protein $[2,3]$. These pathological changes in the brains of $\mathrm{AD}$ patients represent important targets for diagnosis and treatment [3].

The motor symptoms and mechanisms of PD are well known, including age-dependent uncontrollable tremors, postural imbalance, and slowness of movement and rigidity which are caused by the degeneration of dopaminergic neurons in the substantia nigra pars compacta (SNc) located in the midbrain

Corresponding author: Seong-Ho Koh (iD http://orcid.org/0000-0001-5419-5761 Department of Neurology, Hanyang University Guri Hospital, Hanyang University College of Medicine, 153 Gyeongchun-ro, Guri 11923, Korea E-mail: ksh213@hanyang.ac.kr / Tel: +82-31-560-2267 / Fax: +82-31-560-2267 Submitted: November 16, 2016 / Accepted after revision: December 12, 2016 c) (1) \$ This is an Open Access article distributed under the terms of the Creative Commons Attribution Non-Commercial License (http://creativecommons.org/licenses/by-nc/4.0/) which permits unrestricted non-commercial use, distribution, and reproduction in any medium, provided the original work is properly cited. 
[4]. The neuropathological hallmarks of PD are eosinophilic intracellular inclusion bodies termed Lewy-bodies, and argyrophilic processes (Lewy neurites) [5].

The pathophysiology of IS is provoked by a reduction or complete blockage in blood supply to the brain, leading to dysfunction in the ischemic area [6]. The main causes of ischemia are thrombosis, embolism, systemic hypoperfusion, or lacunar infarction from small vessel disease. Various neurologic deficits remain after IS attacks.

There is currently no effective therapeutic strategy for addressing the neurological deficits after the development of these major neurological disorders. However, adult neurogenesis has become a topic of interest, since it was reported that the brain has the capability to generate new neurons from self-renewing and multipotent adult neural stem cells (NSCs) placed in the subventricular zone (SVZ) and subgranular zone (SGZ) of the dentate gyrus [7-11]. Therefore, the objective of this review is to evaluate possible therapeutic neurogenesis strategies for the treatment of neurological deficits in patients diagnosed with $\mathrm{AD}, \mathrm{PD}$, and IS.

\section{BASIC CONCEPTS OF NEUROGENESIS IN THE ADULT BRAIN}

Altman and colleagues first described continuous adult hippocampal neurogenesis in the rat brain in 1965, and this finding changed the idea that it was not possible for the mammalian brain to generate new neurons [12]. In addition, Temple reported multipotent, self-renewing progenitor and stem cells in the SVZ in 1989 [13]. Numerous studies have supported and reinforced these theories since that time [5,7-11,14-17]. Therefore, it is believed that adult NSCs located in the SVZ and SGZ of the dentate gyrus have the ability to proliferate and differentiate in order to replace lost or damaged neural cells throughout life. NSCs are able to differentiate into neurons and glial cells including astrocytes, oligodendrocytes and ependymal cells [18].

Diseased or damaged neurons in patients with neurological disorders lead to problems in normal function of synaptic transmission which is associated with axonal and dendritic degeneration [19]. Therefore, impaired adult neurogenesis occurs in patients with neurological diseases including $\mathrm{AD}, \mathrm{PD}$, and $\mathrm{IS}$, and this leads to deterioration in the adult brain's endogenous capacity for cell renewal in addition to loss of existing neurons due to the disease process and normal aging. However, NSCs in the adult brain can also be activated during disease processes. Previous studies have reported that stromal cell-derived factor$1 a$ promoted neurogenesis via activation of NCSs in the adult brain during the disease process [20,21]. Exposure of stromal cell-derived factor-1 $\alpha$ to quiescent NSCs enhances proliferation, promotes chain migration and transmigration, and activates intracellular molecular pathways mediating engagement [20]. In addition, individual neurogenesis might be affected from the perspective of the neurodevelopmental process. A recent study using human cells reported that there were deficits in the generation of hippocampal granule neurons from schizophrenic human pluripotent stem cell-derived hippocampal NCSs with reduced neuronal activity and frequency of spontaneous neurotransmitter release [22]. Therefore, determination of a clear mechanism in the development and activation of endogenous neurogenesis may be an ideal option for screening and treatment of neurological diseases. However, a therapeutic strategy for the treatment of neurologic diseases using endogenous neurogenesis is limited because of the continuous decline in the number and capacity of NCSs due to the disease process and aging $[6,23]$. Consequently, many studies have attempted to evaluate the efficacy of exogenous stem cell transplantation into the brains of patients with neurologic diseases [24-28]. However, unexpected complications have been reported including the inability of these cells to differentiate into specific types of neuron, and the risk of malignant transformation and immune rejection after NSCs transplantation [6].

\section{ADULT NEUROGENESIS IN ALZHEIMER DISEASE}

German psychiatrist and neuropathologist Alois Alzheimer first described the most common form of dementia in 1906. $\mathrm{AD}$ is the most frequent type of dementia that occurs in middle to late life [29]. It is characterized by widespread neurodegeneration throughout the basal forebrain, cortex, and limbic system as a result of neuronal and synaptic loss [30]. Neuropathologic hallmarks of $\mathrm{AD}$ are the presence of amyloid plaques and neurofibrillary tangles. $A \beta$ is the product of amyloid precursor protein (APP) proteolysis by $\beta$ and $\gamma$-secretase enzymes [31].

In the genetic aspect, mutations in the substrate APP and in the $\gamma$-secretase component presenilin 1 and 2 have been reported to cause familial AD [32-34]. These genetic mutations induce development of the toxic $A \beta$ oligomers and result in deposition and accumulation of $A \beta$ species, especially of the $A \beta 42$ 

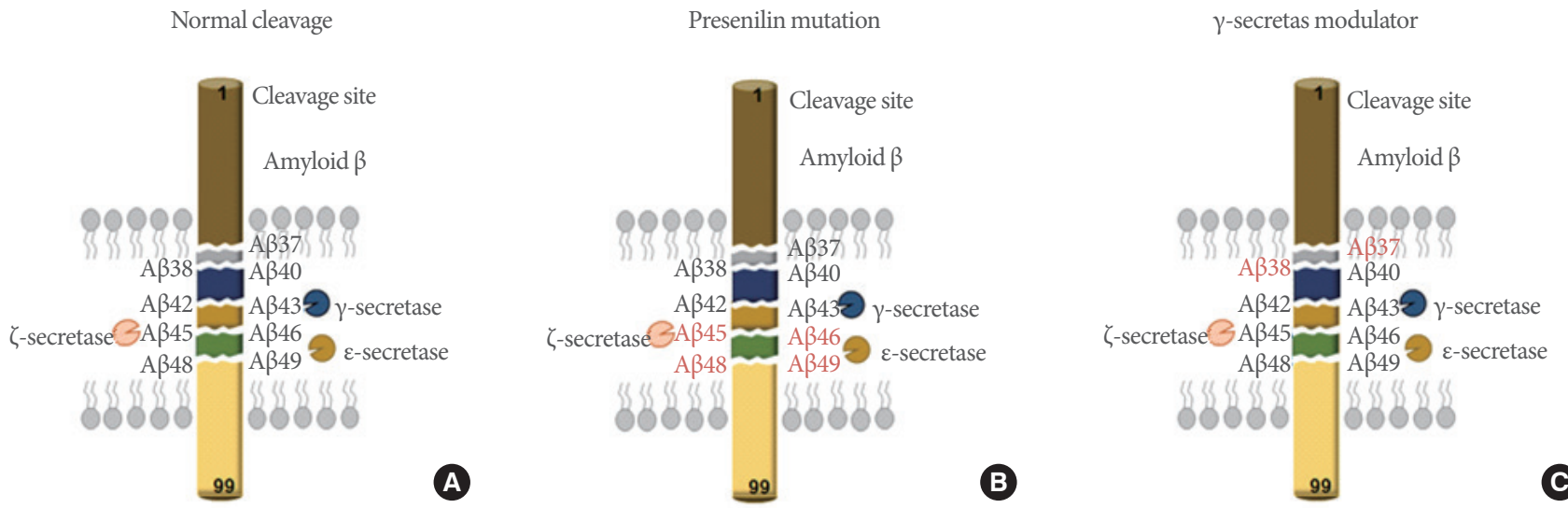

Fig. 1. Stepwise cleavage processing of the $\beta$-carboxyl terminal fragment of $\beta$-amyloid precursor protein by $\gamma$-secretase generates $A \beta$. (A) Normal: $\gamma$-secretase cleaves cleavage site 99 sequentially and $A \beta$ production steps forward via 2 product lines (from $A \beta_{49}$ to $A \beta_{40}$ or from $A \beta_{48}$ to $A \beta_{42}$ ). (B) An Alzheimer disease patient with a presenilin mutation: occurrences of inappropriate cleavage lead to an increase in the $A \beta 42: A \beta 40$ ratio and produce longer toxic forms of the $A \beta$ peptide. (C) $\gamma$-secretase modulator: the $\gamma$-secretase modulator preferentially enhances cleavage activity leading to production of the shorter nontoxic $A \beta$ species $A \beta_{38}$ and $A \beta_{37}$ from the longer toxic forms.

peptide in intracellular and/or extracellular spaces [30,31]. A study using triple transgenic mice harboring three mutant genes (APP, presenilin 1, and tau) showed that the reduction in neurogenesis was directly associated with the presence of $A \beta$ plaques in the hippocampus [35]. In addition, $A \beta$ induced alterations in GABAergic neurotransmission or an imbalance between GABAergic and glutamatergic neurotransmission, both of which contributed to impaired neurogenesis in $\mathrm{AD}[30,36]$. Therefore, it is believed the production of toxic $A \beta 42$ should be one of the important targets to enhance neurogenesis in $\mathrm{AD}$ patients. It is now well accepted that the increase in $A \beta 42$ plaques is due to a reduction in the efficiency of $\gamma$-secretase to process its substrate rather than an increased production of $A \beta$ $[37,38]$.

Initially, many researchers investigated the clinical efficacy of $\gamma$-secretase inhibitors for $\mathrm{AD}$ patients to prevent the production of toxic $A \beta 42$ peptides. However, many side effects including cognitive decline, weight loss, skin cancers and gastrointestinal infections induced by the inhibition of Notch processing were found in clinical trials [39-41]. Modulators of $\gamma$-secretase have been investigated as new drugs for $\mathrm{AD}$ that could preferentially increase the concentration of the shorter nontoxic $A \beta$ species from longer toxic forms [38,42,43] (Fig. 1). However, further investigations including $\mathrm{AD}$ transgenic animal models under similar conditions and clinical trials are needed to prove the efficacy and safety of the $\gamma$-secretase modulators.

The apolipoprotein E4 (apoE4) allele is the major genetic risk factor for sporadic $\mathrm{AD}$ due to the higher prevalence and earlier onset of $\mathrm{AD}$ in apoE4 carriers [44]. In response to central nervous system stress or injury, neurons can synthesize ApoE to protect against neuronal injury or to promote neuronal regeneration [45]. However, ApoE4 among the ApoE family uniquely undergoes neuron-specific proteolysis, resulting in bioactive toxic fragments that enter the cytosol, alter the cytoskeleton, disrupt mitochondrial energy balance, and cause cell death [46]. $\mathrm{Li}$ et al. demonstrated that ApoE4 altered signaling that promoted glial differentiation leading to a detrimental effect on adult hippocampal neurogenesis [47]. Accumulating data suggest the neurodegenerative toxic effect of ApoE4 is caused by a domain interaction (Arg-61 in the N-terminal domain interacts with Glu-255 in the C-terminal domain) [44-46]. Therefore, agents capable of converting ApoE4 to an ApoE3-like molecule by disrupting the domain interaction would be one of the potential therapeutic strategies for promoting neurogenesis in $\mathrm{AD}$ patients [46] (Fig. 2).

Mesenchymal stem cells (MSCs) inhibit apoptosis and inflammation, modulate the immune response in damaged tissues, and promote endogenous neurogenesis and neuroprotection $[48,49]$ Repeated administration of human umbilical cord blood MSCs into the cerebrospinal fluid of the mouse resulted in enhancement of endogenous adult hippocampal neurogenesis and synaptic activity through the paracrine actions of growth differentiation factor-15, which is a human umbilical cord blood-MSC-secreted paracrine factor, suggesting a possi- 

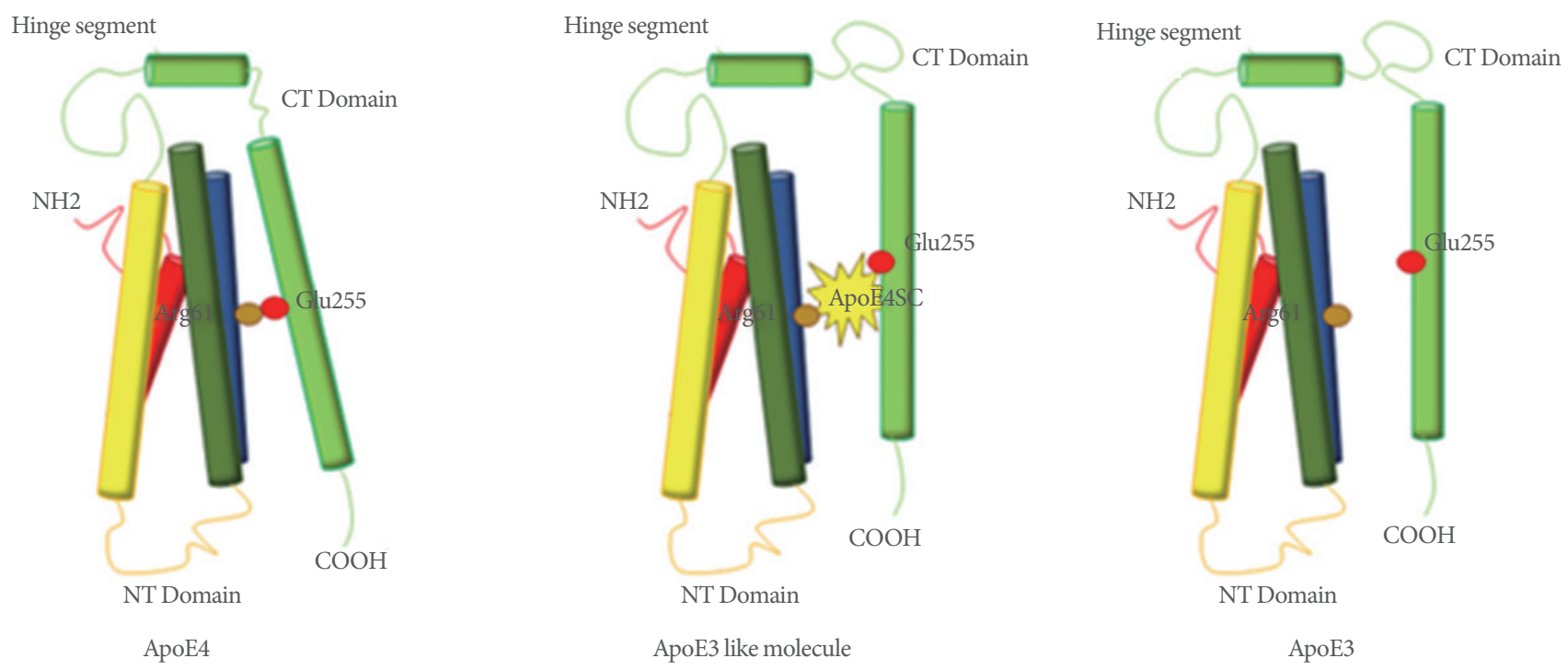

Fig. 2. Apolipoprotein E4 (ApoE4) domain interaction is caused by the ionic interaction between arg-61 in the amino-terminal domain and glu-255 in the carboxyl-terminal domain. The ionic interaction between arg- 61 and glu- 255 in the ApoE4 domain can be blocked by a small-molecule which converts ApoE4 to an ApoE3-like molecule both structurally and functionally. CT, carboxyl terminus; $\mathrm{NH}$, amine; $\mathrm{NT}$, amino terminus; $\mathrm{COOH}$, carboxyl.

ble role for human umbilical cord blood-MSCs as a therapeutic agent for AD [50]. In addition, NSC transplantation in APP/ presenilin 1 transgenic mice significantly improved cognitive deficits and decreased the expression of proinflammatory mediators via suppression of the glial and toll-like receptor 4 (TLR4) inflammatory pathway [51]. This data suggests that these inflammatory pathways may potentially be important therapeutic targets to prevent or delay $\mathrm{AD}$.

Urinary incontinence often occurs in patients suffering from AD. A recent study showed an altered voiding behavior in a transgenic mouse model of $\mathrm{AD}$ [52]. The authors explained that the reason of voiding alterations in the APP/presenilin 1 of mice could be because of the changes in related to anxiety and general locomotor behavior, specific of AD. The exact underlying mechanism between $\mathrm{AD}$ and altered voiding behavior needs to be elucidated in future research.

\section{ADULT NEUROGENESIS IN PARKINSON DISEASE}

$\mathrm{PD}$ is the second most common neurodegenerative disorder after AD [29]. PD is well known as a progressive, chronic neurodegenerative disease causing motor disorders such as hypokinesia, rigidity, tremor, and postural instability as well as exhibiting nonmotor symptoms including depression, anxiety, cogni- tive and olfactory deficits, and autonomic dysfunction [30]. The pathological hallmarks of PD, include Lewy body dementia, loss of dopaminergic neurons in the substantia nigra pars compacta and formation of Lewy bodies and Lewy neurites in surviving neurons [4]. Currently, there is no treatment to prevent disease progression and neurodegeneration, although administration of L-dopa temporarily relieves parkinsonism symptoms [4].

It is accepted that LIM homeobox transcription factor $(\operatorname{Lmx}) 1 \mathrm{a} / \mathrm{b}$ and Msh homeobox 1 (Msx1) which are induced by Lmxla are critical intrinsic factors related to dopamine neurogenesis [53-56]. Multiple factors include two critical pathways (i.e., sonic hedgehog [Shh]- Forkhead box protein [Fox] A2 and Wnt1-Lmxla) which are associated with the development of midbrain dopaminergic neurons. Nuclear receptor related 1 protein (Nurr1) is also known as a key regulator of midbrain dopaminergic neurons [57] (Fig. 3). Therefore, reactivation of these factors involved in dopamine neurogenesis during development may suggest essential therapeutic strategies for PD. Recently, Hedlund et al. [58] reported that Lmxla and other progenitor markers remained in the midbrain aqueductal zone beyond the normal period of dopamine neurogenesis and their proliferation could be stimulated by dopamine receptor antagonists, leading to increased neurogenesis. These results indicate the potential for reactivation of dopamine neurogenesis in adult 


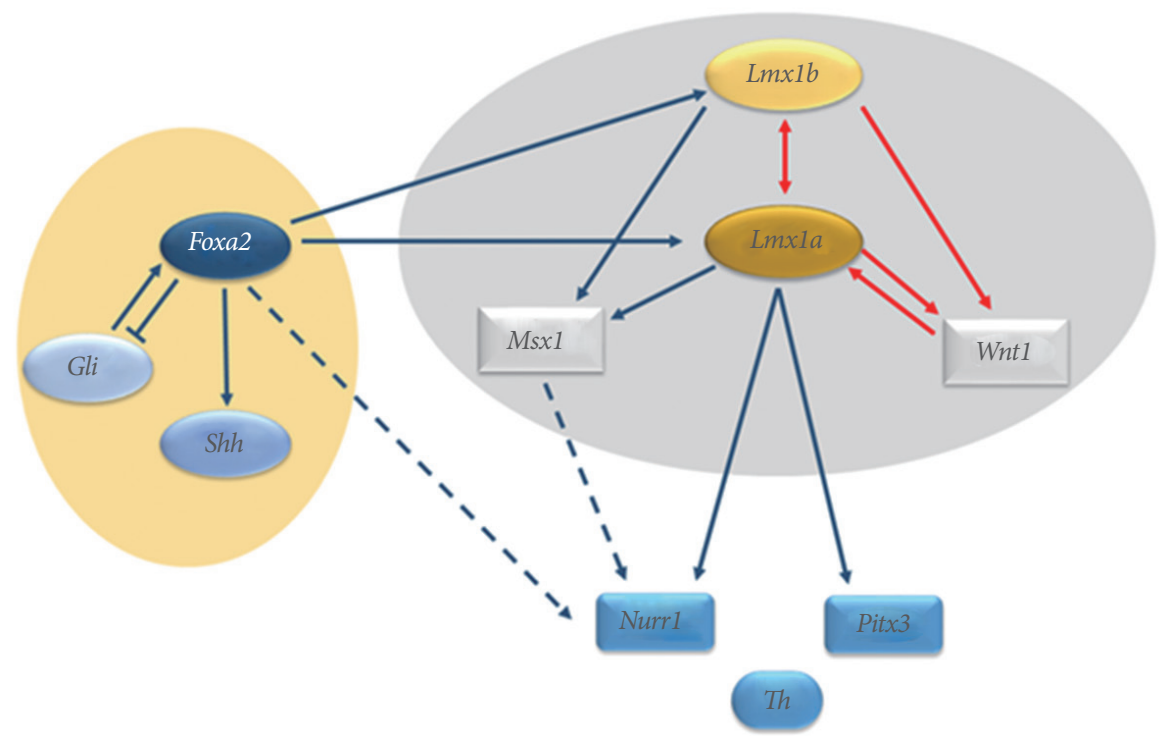

Fig. 3. $L m x 1 b$ expression in the midbrain directly regulates the expression of Wnt1 and $L m x 1 a$. The mutual regulation activities are shown between $L m x 1 b$ and $L m x 1 a$ and between $L m x 1 a$ and Wnt1, forming an auto-regulatory loop (red arrows). Foxa2 directly regulates $S h h$ and $L m x 1 a / b$ to induce specification of midbrain dopaminergic neurons. Lmxla directly regulates the expression of key regulators of midbrain dopaminergic neurons, such as Nurr1 and Pitx3, which in turn regulate tyrosine hydroxylase. The Nurr1 and Pitx3 genes are also regulated by Foxa2, Msx1, and Wht1. Lmx, LIM homeobox transcription factor; Fox, Forkhead box protein; Shh, sonic hedgehog; Nurr1, nuclear receptor related 1 protein; Pitx3, paired like homeodomain 3; Th, tyrosine hydroxylase; Msx1, Msh homeobox 1 .

midbrain dopamine progenitor cells. In addition, Nurr1 agonists showed neuroprotective effects on midbrain dopaminergic neurons and were associated with significant improvements in behavioral deficits in a rat model of PD [57].

$\alpha$-Synuclein is a well-known modulator of adult neurogenesis and is a key protein in PD and Lewy body dementia [59]. Winner and colleagues reported that increasing amounts of $\alpha$-synuclein were associated with a negative impact on adult hippocampal neurogenesis and dendritic development in newborn neurons [60]. Activation of the cAMP response elementbinding protein (CREB) pathway by the phosphodiesterase inhibitor rolipram showed partial improvement of the dendrite outgrowth defect in mice overexpressing $\alpha$-synuclein [60]. A recent study using a transgenic rat model of $\mathrm{PD}$ showed that accumulating $\alpha$-synuclein and impaired 5-HT neurotransmission severely affected hippocampal neurogenesis prior to the onset of aggregation pathology and motor deficits [61].

Leucine rich repeat kinase 2 (LRRK2) is a large multidomain protein bearing GTPase and kinase activity, and mutations in this gene represent one of the stronger risk factors for the development of Parkinson disease [62,63]. Although the underlying pathogenesis of PD remains poorly understood, increased
LRRK2 kinase activity, which is caused by the G2019S mutation, is thought to be associated with LRRK2-linked PD [64] (Fig. 4). Several studies have shown dopaminergic neurodegeneration from cultured dopaminergic neurons of pluripotent stem cells from PD patients harboring the LRRK2-G2019S mutation and human LRRK2-G2019S-expressing transgenic mice [65-67]. The potential relationship between LRRK2, $\alpha$-synuclein, and tau in inducing PD pathogenesis has been suggested [62, $63,68,69]$. LRRK2 functions upstream of pathogenic effects through $\alpha$-synuclein, tau or both proteins [70] (Fig. 4). Therefore, PD pathogenesis induced by LRRK2 may be a potential new target as a therapeutic strategy for patients with PD.

In recent years, induced pluripotent stem cells (iPS cells) through somatic cell reprogramming have drawn attention from researchers because of their many beneficial effects on neurodegenerative diseases such as PD [71]. In addition, iPS cells can be generated from autologous cells and are able to overcome the barriers of allogenic cell transplantation [72,73]. Han and colleagues demonstrated that PD rats with iPS cell-derived NSCs transplanted into the striatum showed improvement in functional defects of rotational asymmetry. In addition, iPS cell-derived NSCs were found to survive and integrate into 

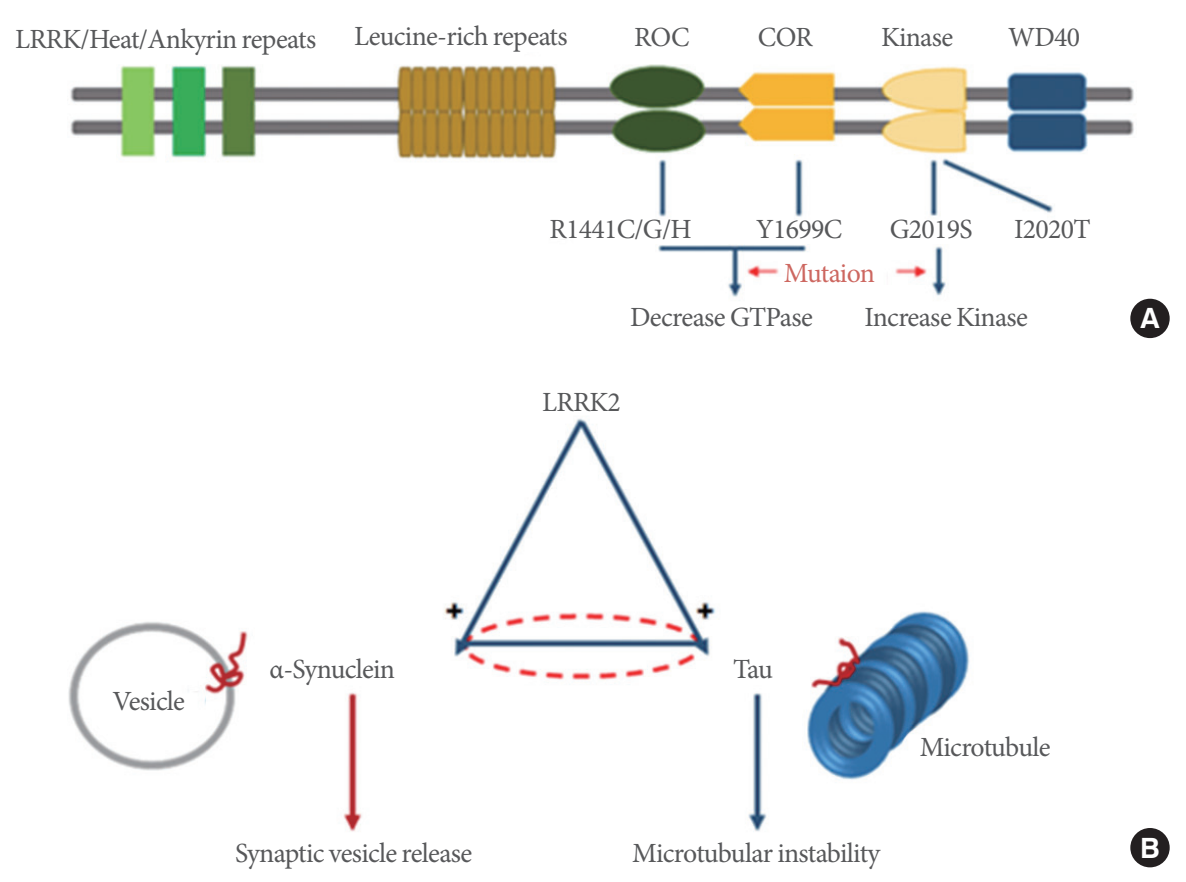

Fig. 4. Schematic drawings of domains and mutations of leucine rich repeat kinase 2 (LRRK2) and the relationship between LRRK2, a-synuclein and tau protein. (A) LRRK2 is a large multidomain protein containing GTPase and kinase activity and mutations. LRRK2 domains are composed of a GTP-binding ras of complex protein (ROC) domain, a carboxy-terminal of ROC (COR) domain and a kinase domain. Both R1441 and Y1699 mutations in LRRK2 decrease GTPase activity, whereas G2019S increases kinase activity in LRRK2. (B) LRRK2 functions upstream of pathogenic effects through $\alpha$-synuclein, tau or both proteins. The mutual influence between $\alpha$-synuclein and tau is less obvious (dashed line). Dysfunctions in $\alpha$-synuclein and tau cause synaptic vesicle release and microtubular instability.

the brain of transplanted PD rats and differentiate into neurons, including dopaminergic neurons in vivo [71]. Based on these findings, clinical application of iPS cells for neurodegenerative diseases, including PD, may be an important new therapeutic strategy in the near future.

It is well known that the loss of dopaminergic activity (physiologic inhibition of the micturition reflex mediated by dopaminergic D1 activity) leads to overactivity of the micturition reflex [74]. The pontine micturition center or Barrington's nucleus is gaining particular importance due to: (1) recent findings of a-synuclein in Barrington's nucleus, (2) known urinary dysfunction in parkinsonian patients, other patients with dementia and in very old individuals; and (3) its proximity to the pedunculopontine nucleus, a surgical target in deep brain stimulation for PD patients. Campeau et al. [75] reported that the transplantation of bone marrow derived mesenchymal stromal cells into the substantia nigra pars compacta, which improved the urodynamic pressure by 42 days, compared to the control group. The authors described that more tyrosine hydroxylase positive neurons were observed in the treated substantia nigra pars compacta.

\section{ADULT NEUROGENESIS IN ISCHEMIC STROKE}

Stroke remains a major cause of morbidity and mortality around the world [76]. There are various reasons for IS occurrence including thrombosis, embolism, systemic hypoperfusion, or venous thrombosis. When cerebral blood flow is reduced, the affected parts of the brain experience oxygen deprivation. Decreased oxygen delivery results in activation of cellular anaerobic metabolism leading to the depletion of glucose, which is the only source of energy in the brain. This ischemic cascade causes neuronal damage and ionic pump failure in the brain due to energy depletion, and ultimately leads to necrosis and apoptosis of neurons and glial cells resulting in irreversible injury to core regions with partially reversible damage in the surrounding penumbra zone [6].

The occurrence of stroke-induced compensatory endogenous neurogenesis has been demonstrated in the adult human brain [77-79]. The SVZ is well known as the main source of 


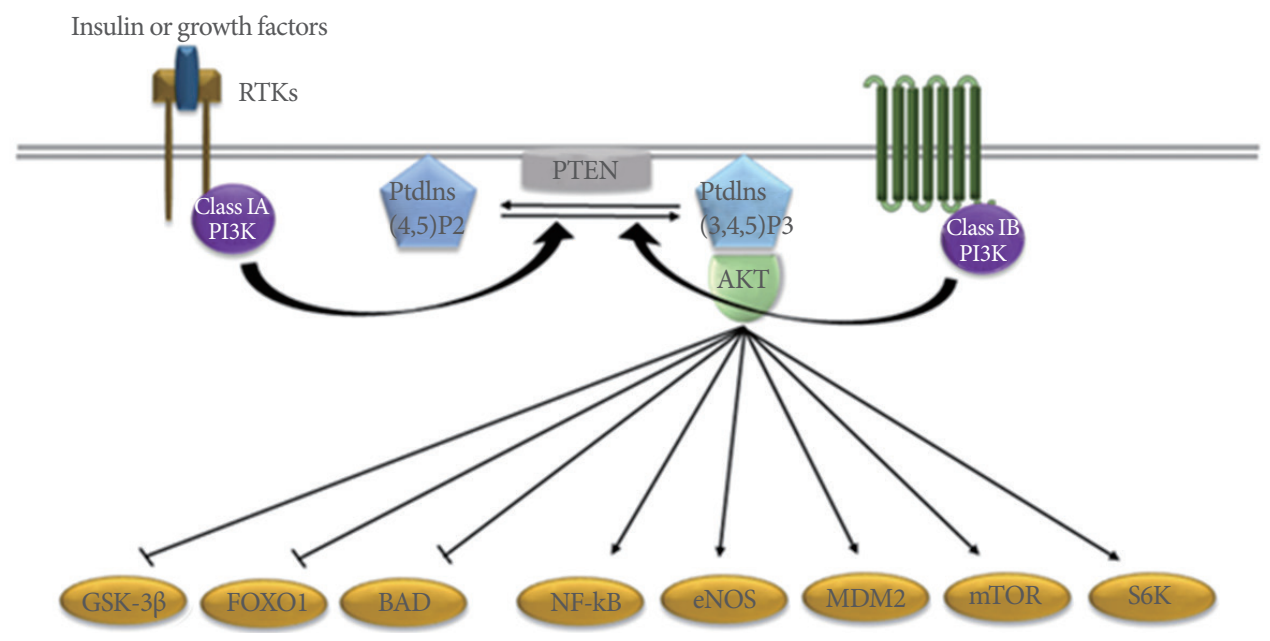

Fig. 5. Phosphatidylinositol 3-kinase (PI3K) pathway: Activation of class IA/B PI3Ks occurs through the stimulation of receptor tyrosine kinases, which is induced by insulin and the concomitant assembly of receptor-PI3K complexes. Activated PI3Ks catalyze the conversion of PtdIns(4,5)P2 to PtdIns(3,4,5)P3. PtdIns(3,4,5)P3 serves as a second messenger that helps to activate protein kinase B (AKT). Through phosphorylation, activated AKT affects many important downstream signals, including mouse double minute 2 homolog (MDM2), nuclear factor kappa-light-chain-enhancer of activated B cells (NF-kB), endothelial nitric oxide synthase (eNOS), mammalian target of rapamycin (mTOR), and S6 kinase, and inhibits Forkhead box O (FOXO)s, Bcl-2-associated death promoter (BAD), and glycogen synthase kinase (GSK)-3ß. RTKs, receptor tyrosine kinases; Ptdlns, phosphatidylinositol; PTEN, phosphatase and tensin homolog; SGK, serine/threonine-protein kinase; S6K, ribosomal protein S6 kinase.

NSCs that are generated after a stroke which migrate toward the damaged area [80-83]. In addition, ischemia-induced neurogenesis occurs in areas that are non-neurogenic in the intact brain (e.g., the striatum and cerebral cortex) as well as in areas where new neurons normally form, such as the SVZ and SGZ [84]. Several studies found that there is increased neurogenic activity in the ischemic penumbra distant from the SVZ as well as in the neurogenic region of the lateral ventricular wall in the human brain after stroke $[77,78,85]$. However, the limited number and capacity of NCSs due to stroke attacks and normal aging may lead to a decrease in the number and maturation of newly generated neurons in the ischemic penumbra of the cerebral cortex. A recent study demonstrated that stroke-generated neuroblasts $\left(\mathrm{DCX}^{+} / \mathrm{BrdU}^{+}\right)$were observed in the peri-infarct cortex within two weeks after IS. However, they failed to detect the same neuroblast markers in these cells and there was no differentiation to mature neurons after 4 weeks [86].

Strategies to stimulate ischemia-induced neurogenesis seem to follow these steps: (1) proliferation of NCSs, (2) survival of immature or mature neurons, (3) migration of new neuroblasts to the appropriate location, (4) differentiation of new neuroblasts to the phenotype of neurons that need to be replaced, and (5) development of functional synaptic connectivity counter- acting disease symptoms [84].

Glial cell-derived neurotrophic factor (GDNF), which is a nerve growth factor, is associated with neurogenesis after stroke [87-90]. A recent study in a rat neonatal ischemic model reported that the infusion of GDNF promoted endogenous selfrepair by stimulating proliferation of glial progenitor cells derived from both the SVZ and white matter, activating their differentiation into more mature oligodendrocytes and raising the survival rate of these newly generated glial cells [90]. In addition, phosphatidylinositide 3-kinase (PI3K) is one of the wellestablished pathways affecting cell proliferation, growth, differentiation, motility, survival, and intracellular trafficking [91] (Fig. 5). The PI3K pathway is necessary for the survival of both neurons and NSCs which are essential for endogenous neurogenesis [92-95]. Activated PI3K phosphorylates Akt (protein kinase B), which is a downstream effector. Phosphorylated Akt affects mouse double minute 2 homolog (MDM2), nuclear factor kappa-light-chain-enhancer of activated B cells (NF-kB), endothelial nitric oxide synthase (eNOS), mammalian target of rapamycin (mTOR), and S6 kinase and inhibits Forkhead box $\mathrm{O}$ (FOXO), BAD, and glycogen synthase kinase (GSK)-3ß. All of these signals contribute to the protection and neurogenesis of NSCs [91]. 
Transplantation of neuronal precursors derived from human embryonic stem cells has been reported to reduce infarct volume and improve behavioral outcomes after distal middle cerebral artery occlusion in rats [96-98]. Jin et al. [96] demonstrated that transplantation increased neurogenesis in the ipsilateral SVZ, but not in the contralateral SVZ or either SGZ in both young adult (3 months old) and aged ( 24 months old) rats with focal cerebral ischemia. These findings suggest that transplantation of NCSs for stroke treatment may be associated with changes in endogenous adaptive processes of neurogenesis. Therefore, transplantation of NCSs with stimulation of endogenous neurogenesis may be a potential therapeutic strategy for stroke recovery in the future.

Neurogenic lower urinary tract dysfunction is a major problem in patients with various neurological disorders, and may result in debilitating symptoms and serious complications, including chronic renal failure and recurrent urinary tract infections [99]. ISs are known as inducing not only bladder overactivity, but also stress urinary incontinence [100]. After IS occurrence duloxetine, a norepinephrine and serotonin reuptake inhibitor reduced bladder overactivity but failed to enhance active urethral closure mechanisms during sneezing, suggesting that disorganization of the brain network after IS might influence the effect of duloxetine on lower urinary tract function.

\section{CONCLUSIONS}

Currently, there are no effective treatments to improve clinical outcomes of common neurological disorders such as AD, PD, and IS. Therefore, many researchers have an interest in neurogenesis as a new therapeutic strategy for various neurologic diseases. We reviewed the current reliable opinions on the mechanisms and potential clinical applications related to neurogenesis for patients with $\mathrm{AD}, \mathrm{PD}$, and IS. Although there remain many limitations in the clinical application of both endogenous and exogenous neurogenesis for $\mathrm{AD}, \mathrm{PD}$, and IS patients, the accumulated data demonstrates the possibility of overcoming these limitations in the near future. Advances in the field of neurogenesis may bring a better quality of life for patients suffering from these devastating disorders.

\section{REFERENCES}

1. Choi DY, Choi H. Natural products from marine organisms with neuroprotective activity in the experimental models of
Alzheimer's disease, Parkinson's disease and ischemic brain stroke: their molecular targets and action mechanisms. Arch Pharm Res 2015;38:139-70.

2. $\mathrm{Mu}$ Y, Gage FH. Adult hippocampal neurogenesis and its role in Alzheimer's disease. Mol Neurodegener 2011;6:85.

3. Ono M, Watanabe H, Kitada A, Matsumura K, Ihara M, Saji $\mathrm{H}$. Highly selective tau-SPECT imaging probes for detection of neurofibrillary tangles in Alzheimer's disease. Sci Rep 2016;6:34197.

4. Zhang L, Deng J, Pan Q, Zhan Y, Fan JB, Zhang K, et al. Targeted methylation sequencing reveals dysregulated Wnt signaling in Parkinson disease. J Genet Genomics 2016;43:58792.

5. Marxreiter F, Regensburger M, Winkler J. Adult neurogenesis in Parkinson's disease. Cell Mol Life Sci 2013;70:459-73.

6. Koh SH, Park HH. Neurogenesis in Stroke Recovery. Transl Stroke Res 2016 Mar 18 [Epub]. https://doi.org/10.1007/s12975016-0460-z.

7. Ming GL, Song H. Adult neurogenesis in the mammalian brain: significant answers and significant questions. Neuron 2011;70:687-702.

8. Alvarez-Buylla A, Lim DA. For the long run: maintaining germinal niches in the adult brain. Neuron 2004;41:683-6.

9. Gage FH. Mammalian neural stem cells. Science 2000;287: 1433-8.

10. Luskin MB, Zigova T, Soteres BJ, Stewart RR. Neuronal progenitor cells derived from the anterior subventricular zone of the neonatal rat forebrain continue to proliferate in vitro and express a neuronal phenotype. Mol Cell Neurosci 1997; 8:351-66.

11. Huttner WB. Stem cells: slow and steady wins the race. Nat Neurosci 2015;18:613-4.

12. Altman J, Das GD. Autoradiographic and histological evidence of postnatal hippocampal neurogenesis in rats. J Comp Neurol 1965;124:319-35.

13. Temple S. Division and differentiation of isolated CNS blast cells in microculture. Nature 1989;340:471-3.

14. Bayer SA. Development of the hippocampal region in the rat. I. Neurogenesis examined with $3 \mathrm{H}$-thymidine autoradiography. J Comp Neurol 1980;190:87-114.

15. Sakalem ME, Seidenbecher T, Zhang M, Saffari R, Kravchenko M, Wördemann S, et al. Environmental enrichment and physical exercise revert behavioral and electrophysiological impairments caused by reduced adult neurogenesis. Hippocampus 2016 Oct 4 [Epub]. https://doi.org/10.1002/hipo.22669. 
16. Reynolds BA, Weiss S. Generation of neurons and astrocytes from isolated cells of the adult mammalian central nervous system. Science 1992;255:1707-10.

17. Yoo DY, Lee KY, Park JH, Jung HY, Kim JW, Yoon YS, et al. Glucose metabolism and neurogenesis in the gerbil hippocampus after transient forebrain ischemia. Neural Regen Res 2016;11:1254-9.

18. Capilla-Gonzalez V, Herranz-Pérez V, García-Verdugo JM. The aged brain: genesis and fate of residual progenitor cells in the subventricular zone. Front Cell Neurosci 2015;9:365.

19. Luo L, O'Leary DD. Axon retraction and degeneration in development and disease. Annu Rev Neurosci 2005;28:12756.

20. Imitola J, Raddassi K, Park KI, Mueller FJ, Nieto M, Teng YD, et al. Directed migration of neural stem cells to sites of CNS injury by the stromal cell-derived factor 1alpha/CXC chemokine receptor 4 pathway. Proc Natl Acad Sci U S A 2004;101:18117-22.

21. Li Y, Huang J, He X, Tang G, Tang YH, Liu Y, et al. Postacute stromal cell-derived factor-1 $\alpha$ expression promotes neurovascular recovery in ischemic mice. Stroke 2014;45:1822-9.

22. Yu DX, Di Giorgio FP, Yao J, Marchetto MC, Brennand K, Wright R, et al. Modeling hippocampal neurogenesis using human pluripotent stem cells. Stem Cell Reports 2014;2:295310.

23. Encinas JM, Michurina TV, Peunova N, Park JH, Tordo J, Peterson DA, et al. Division-coupled astrocytic differentiation and age-related depletion of neural stem cells in the adult hippocampus. Cell Stem Cell 2011;8:566-79.

24. Zhang P, Xie MQ, Ding YQ, Liao M, Qi SS, Chen SX, et al. Allopregnanolone enhances the neurogenesis of midbrain dopaminergic neurons in APPswe/PSEN1 mice. Neuroscience 2015;290:214-26.

25. Gonzalez FF, Larpthaveesarp A, McQuillen P, Derugin N, Wendland M, Spadafora R, et al. Erythropoietin increases neurogenesis and oligodendrogliosis of subventricular zone precursor cells after neonatal stroke. Stroke 2013;44:753-8.

26. Abeysinghe HC, Bokhari L, Quigley A, Choolani M, Chan J, Dusting GJ, et al. Pre-differentiation of human neural stem cells into GABAergic neurons prior to transplant results in greater repopulation of the damaged brain and accelerates functional recovery after transient ischemic stroke. Stem Cell Res Ther 2015;6:186.

27. Chen P, Yan Q, Wang S, Wang C, Zhao P. Transfer of three transcription factors via a lentiviral vector ameliorates spa- tial learning and memory impairment in a mouse model of Alzheimer's disease. Gene 2016;587:59-63.

28. Wei L, Fraser JL, Lu ZY, Hu X, Yu SP. Transplantation of hypoxia preconditioned bone marrow mesenchymal stem cells enhances angiogenesis and neurogenesis after cerebral ischemia in rats. Neurobiol Dis 2012;46:635-45.

29. Duarte-Neves J, Pereira de Almeida L, Cavadas C. Neuropeptide Y (NPY) as a therapeutic target for neurodegenerative diseases. Neurobiol Dis 2016;95:210-24.

30. Winner B, Winkler J. Adult neurogenesis in neurodegenerative diseases. Cold Spring Harb Perspect Biol 2015;7:a021287.

31. Crews L, Rockenstein E, Masliah E. APP transgenic modeling of Alzheimer's disease: mechanisms of neurodegeneration and aberrant neurogenesis. Brain Struct Funct 2010; 214:111-26.

32. Sherrington R, Rogaev EI, Liang Y, Rogaeva EA, Levesque $\mathrm{G}$, Ikeda $\mathrm{M}$, et al. Cloning of a gene bearing missense mutations in early-onset familial Alzheimer's disease. Nature 1995;375:754-60.

33. Rogaev EI, Sherrington R, Rogaeva EA, Levesque G, Ikeda M, Liang Y, et al. Familial Alzheimer's disease in kindreds with missense mutations in a gene on chromosome 1 related to the Alzheimer's disease type 3 gene. Nature 1995;376:7758.

34. Goate A, Chartier-Harlin MC, Mullan M, Brown J, Crawford F, Fidani L, et al. Segregation of a missense mutation in the amyloid precursor protein gene with familial Alzheimer's disease. Nature 1991;349:704-6.

35. Rodríguez JJ, Jones VC, Tabuchi M, Allan SM, Knight EM, LaFerla FM, et al. Impaired adult neurogenesis in the dentate gyrus of a triple transgenic mouse model of Alzheimer's disease. PLoS One 2008;3:e2935.

36. Sun B, Halabisky B, Zhou Y, Palop JJ, Yu G, Mucke L, et al. Imbalance between GABAergic and glutamatergic transmission impairs adult neurogenesis in an animal model of Alzheimer's disease. Cell Stem Cell 2009;5:624-33.

37. Blain JF, Bursavich MG, Freeman EA, Hrdlicka LA, Hodgdon HE, Chen T, et al. Characterization of FRM-36143 as a new $\gamma$-secretase modulator for the potential treatment of familial Alzheimer's disease. Alzheimers Res Ther 2016;8:34.

38. Bursavich MG, Harrison BA, Blain JF. Gamma secretase modulators: new Alzheimer's drugs on the horizon? J Med Chem 2016;59:7389-409.

39. Doody RS, Raman R, Farlow M, Iwatsubo T, Vellas B, Joffe $\mathrm{S}$, et al. A phase 3 trial of semagacestat for treatment of Al- 
zheimer's disease. N Engl J Med 2013;369:341-50.

40. De Strooper B. Lessons from a failed $\gamma$-secretase Alzheimer trial. Cell 2014;159:721-6.

41. Coric V, van Dyck CH, Salloway S, Andreasen N, Brody M, Richter RW, et al. Safety and tolerability of the $\gamma$-secretase inhibitor avagacestat in a phase 2 study of mild to moderate Alzheimer disease. Arch Neurol 2012;69:1430-40.

42. Weggen S, Eriksen JL, Das P, Sagi SA, Wang R, Pietrzik CU, et al. A subset of NSAIDs lower amyloidogenic Abeta42 independently of cyclooxygenase activity. Nature 2001;414:212-6.

43. Oehlrich D, Rombouts FJ, Berthelot D, Bischoff FP, De Cleyn MA, Jaroskova L, et al. Design and synthesis of bicyclic heterocycles as potent $\gamma$-secretase modulators. Bioorg Med Chem Lett 2013;23:4794-800.

44. Adeosun SO, Hou X, Zheng B, Stockmeier C, Ou X, Paul I, et al. Cognitive deficits and disruption of neurogenesis in a mouse model of apolipoprotein E4 domain interaction. J Biol Chem 2014;289:2946-59.

45. Chen HK, Ji ZS, Dodson SE, Miranda RD, Rosenblum CI, Reynolds IJ, et al. Apolipoprotein E4 domain interaction mediates detrimental effects on mitochondria and is a potential therapeutic target for Alzheimer disease. J Biol Chem 2011;286:5215-21.

46. Mahley RW, Weisgraber KH, Huang Y. Apolipoprotein E4: a causative factor and therapeutic target in neuropathology, including Alzheimer's disease. Proc Natl Acad Sci U S A 2006;103:5644-51.

47. Li G, Bien-Ly N, Andrews-Zwilling Y, Xu Q, Bernardo A, Ring $\mathrm{K}$, et al. GABAergic interneuron dysfunction impairs hippocampal neurogenesis in adult apolipoprotein E4 knockin mice. Cell Stem Cell 2009;5:634-45.

48. Kim JY, Jeon HB, Yang YS, Oh W, Chang JW. Application of human umbilical cord blood-derived mesenchymal stem cells in disease models. World J Stem Cells 2010;2:34-8.

49. Hsieh JY, Wang HW, Chang SJ, Liao KH, Lee IH, Lin WS, et al. Mesenchymal stem cells from human umbilical cord express preferentially secreted factors related to neuroprotection, neurogenesis, and angiogenesis. PLoS One 2013;8: e72604.

50. Kim DH, Lee D, Chang EH, Kim JH, Hwang JW, Kim JY, et al. GDF-15 secreted from human umbilical cord blood mesenchymal stem cells delivered through the cerebrospinal fluid promotes hippocampal neurogenesis and synaptic activity in an Alzheimer's disease model. Stem Cells Dev 2015;24: 2378-90.
51. Zhang Q, Wu HH, Wang Y, Gu GJ, Zhang W, Xia R. Neural stem cell transplantation decreases neuroinflammation in a transgenic mouse model of Alzheimer's disease. J Neurochem 2015 Nov 3 [Epub]. https://doi.org/10.1111/jnc.13413.

52. Biallosterski BT, Prickaerts J, Rahnama’i MS, de Wachter S, van Koeveringe GA, Meriaux C. Changes in voiding behavior in a mouse model of Alzheimer's disease. Front Aging Neurosci 2015;7:160.

53. Andersson E, Tryggvason U, Deng Q, Friling S, Alekseenko $Z$, Robert B, et al. Identification of intrinsic determinants of midbrain dopamine neurons. Cell 2006;124:393-405.

54. Ono Y, Nakatani T, Sakamoto Y, Mizuhara E, Minaki Y, Kumai $\mathrm{M}$, et al. Differences in neurogenic potential in floor plate cells along an anteroposterior location: midbrain dopaminergic neurons originate from mesencephalic floor plate cells. Development 2007;134:3213-25.

55. Deng Q, Andersson E, Hedlund E, Alekseenko Z, Coppola E, Panman L, et al. Specific and integrated roles of Lmxla, Lmx1b and Phox2a in ventral midbrain development. Development 2011;138:3399-408.

56. Yan CH, Levesque M, Claxton S, Johnson RL, Ang SL. Lmxla and lmxlb function cooperatively to regulate proliferation, specification, and differentiation of midbrain dopaminergic progenitors. J Neurosci 2011;31:12413-25.

57. Kim CH, Han BS, Moon J, Kim DJ, Shin J, Rajan S, et al. Nuclear receptor Nurr1 agonists enhance its dual functions and improve behavioral deficits in an animal model of Parkinson's disease. Proc Natl Acad Sci U S A 2015;112:8756-61.

58. Hedlund E, Belnoue L, Theofilopoulos S, Salto C, Bye C, Parish C, et al. Dopamine receptor antagonists enhance proliferation and neurogenesis of midbrain Lmxla-expressing progenitors. Sci Rep 2016;6:26448.

59. Chandra S, Fornai F, Kwon HB, Yazdani U, Atasoy D, Liu X, et al. Double-knockout mice for alpha- and beta-synucleins: effect on synaptic functions. Proc Natl Acad Sci U S A 2004; 101:14966-71.

60. Winner B, Regensburger M, Schreglmann S, Boyer L, Prots I, Rockenstein E, et al. Role of $\alpha$-synuclein in adult neurogenesis and neuronal maturation in the dentate gyrus. J Neurosci 2012;32:16906-16.

61. Kohl Z, Ben Abdallah N, Vogelgsang J, Tischer L, Deusser J, Amato D, et al. Severely impaired hippocampal neurogenesis associates with an early serotonergic deficit in a BAC a-synuclein transgenic rat model of Parkinson's disease. Neurobiol Dis 2016; 85:206-17. 
62. Cookson MR. The role of leucine-rich repeat kinase 2 (LRRK2) in Parkinson's disease. Nat Rev Neurosci 2010;11: 791-7.

63. Liu GH, Qu J, Suzuki K, Nivet E, Li M, Montserrat N, et al. Progressive degeneration of human neural stem cells caused by pathogenic LRRK2. Nature 2012;491:603-7.

64. Schwab AJ, Ebert AD. Neurite aggregation and calcium dysfunction in iPSC-derived sensory neurons with Parkinson's disease-related LRRK2 G2019S mutation. Stem Cell Reports 2015;5:1039-52.

65. Sánchez-Danés A, Richaud-Patin Y, Carballo-Carbajal I, Jiménez-Delgado S, Caig C, Mora S, et al. Disease-specific phenotypes in dopamine neurons from human iPS-based models of genetic and sporadic Parkinson's disease. EMBO Mol Med 2012;4:380-95.

66. Ramonet D, Daher JP, Lin BM, Stafa K, Kim J, Banerjee R, et al. Dopaminergic neuronal loss, reduced neurite complexity and autophagic abnormalities in transgenic mice expressing G2019S mutant LRRK2. PLoS One 2011;6:e18568.

67. Cooper O, Seo H, Andrabi S, Guardia-Laguarta C, Graziotto J, Sundberg M, et al. Pharmacological rescue of mitochondrial deficits in iPSC-derived neural cells from patients with familial Parkinson's disease. Sci Transl Med 2012;4:141ra90.

68. Weng YH, Chen CY, Lin KJ, Chen YL, Yeh TH, Hsiao IT, et al. (R1441C) LRRK2 induces the degeneration of SN dopaminergic neurons and alters the expression of genes regulating neuronal survival in a transgenic mouse model. Exp Neurol 2016;275 Pt 1:104-15.

69. Wider C, Dickson DW, Wszolek ZK. Leucine-rich repeat kinase 2 gene-associated disease: redefining genotype-phenotype correlation. Neurodegener Dis 2010;7:175-9.

70. Taymans JM, Cookson MR. Mechanisms in dominant parkinsonism: The toxic triangle of LRRK2, alpha-synuclein, and tau. Bioessays 2010;32:227-35.

71. Han F, Wang W, Chen B, Chen C, Li S, Lu X, et al. Human induced pluripotent stem cell-derived neurons improve motor asymmetry in a 6-hydroxydopamine-induced rat model of Parkinson's disease. Cytotherapy 2015;17:665-79.

72. Yu J, Hu K, Smuga-Otto K, Tian S, Stewart R, Slukvin II, et al. Human induced pluripotent stem cells free of vector and transgene sequences. Science 2009;324:797-801.

73. Takahashi K, Tanabe K, Ohnuki M, Narita M, Ichisaka T, Tomoda $\mathrm{K}$, et al. Induction of pluripotent stem cells from adult human fibroblasts by defined factors. Cell 2007;131: 861-72.
74. Blanco L, Ros CM, Tarragón E, Fernández-Villalba E, Herrero MT. Functional role of Barrington's nucleus in the micturition reflex: relevance in the surgical treatment of Parkinson's disease. Neuroscience 2014;266:150-61.

75. Campeau L, Soler R, Sittadjody S, Pareta R, Nomiya M, Zarifpour $\mathrm{M}$, et al. Effects of allogeneic bone marrow derived mesenchymal stromal cell therapy on voiding function in a rat model of Parkinson disease. J Urol 2014;191:850-9.

76. Zhang R, Zhang Z, Chopp M. Function of neural stem cells in ischemic brain repair processes. J Cereb Blood Flow Metab 2016;36:2034-43.

77. Minger SL, Ekonomou A, Carta EM, Chinoy A, Perry RH, Ballard CG. Endogenous neurogenesis in the human brain following cerebral infarction. Regen Med 2007;2:69-74.

78. Jin K, Wang X, Xie L, Mao XO, Zhu W, Wang Y, et al. Evidence for stroke-induced neurogenesis in the human brain. Proc Natl Acad Sci U S A 2006;103:13198-202.

79. Macas J, Nern C, Plate KH, Momma S. Increased generation of neuronal progenitors after ischemic injury in the aged adult human forebrain. J Neurosci 2006;26:13114-9.

80. Jin K, Minami M, Lan JQ, Mao XO, Batteur S, Simon RP, et al. Neurogenesis in dentate subgranular zone and rostral subventricular zone after focal cerebral ischemia in the rat. Proc Natl Acad Sci U S A 2001;98:4710-5.

81. Arvidsson A, Collin T, Kirik D, Kokaia Z, Lindvall O. Neuronal replacement from endogenous precursors in the adult brain after stroke. Nat Med 2002;8:963-70.

82. Zhang RL, Zhang ZG, Zhang L, Chopp M. Proliferation and differentiation of progenitor cells in the cortex and the subventricular zone in the adult rat after focal cerebral ischemia. Neuroscience 2001;105:33-41.

83. Parent JM, Vexler ZS, Gong C, Derugin N, Ferriero DM. Rat forebrain neurogenesis and striatal neuron replacement after focal stroke. Ann Neurol 2002;52:802-13.

84. Lindvall O, Kokaia Z. Neurogenesis following Stroke Affecting the Adult Brain. Cold Spring Harb Perspect Biol 2015;7(11). pii: a019034. https://doi.org/10.1101/cshperspect.a019034.

85. Nakayama D, Matsuyama T, Ishibashi-Ueda H, Nakagomi T, Kasahara Y, Hirose H, et al. Injury-induced neural stem/ progenitor cells in post-stroke human cerebral cortex. Eur J Neurosci 2010;31:90-8.

86. Huttner HB, Bergmann O, Salehpour M, Rácz A, Tatarishvili J, Lindgren $\mathrm{E}$, et al. The age and genomic integrity of neurons after cortical stroke in humans. Nat Neurosci 2014; 17:801-3. 
87. Love S, Plaha P, Patel NK, Hotton GR, Brooks DJ, Gill SS. Glial cell line-derived neurotrophic factor induces neuronal sprouting in human brain. Nat Med 2005;11:703-4.

88. Kobayashi T, Ahlenius H, Thored P, Kobayashi R, Kokaia Z, Lindvall O. Intracerebral infusion of glial cell line-derived neurotrophic factor promotes striatal neurogenesis after stroke in adult rats. Stroke 2006;37:2361-7.

89. Sofroniew MV, Howe CL, Mobley WC. Nerve growth factor signaling, neuroprotection, and neural repair. Annu Rev Neurosci 2001;24:1217-81.

90. Li WJ, Mao FX, Chen HJ, Qian LH, Buzby JS. Treatment with UDP-glucose, GDNF, and memantine promotes SVZ and white matter self-repair by endogenous glial progenitor cells in neonatal rats with ischemic PVL. Neuroscience 2015; 284:444-58.

91. Koh SH, Lo EH. The role of the PI3K pathway in the regeneration of the damaged brain by neural stem cells after cerebral infarction. J Clin Neurol 2015;11:297-304.

92. Tang G, Dong X, Huang X, Huang XJ, Liu H, Wang Y, et al. A natural diarylheptanoid promotes neuronal differentiation via activating ERK and PI3K-Akt dependent pathways. Neuroscience 2015;303:389-401.

93. Tiwari SK, Seth B, Agarwal S, Yadav A, Karmakar M, Gupta SK, et al. Ethosuximide induces hippocampal neurogenesis and reverses cognitive deficits in an amyloid- $\beta$ Toxin-induced Alzheimer rat model via the phosphatidylinositol 3-kinase (PI3K)/Akt/Wnt/ $\beta$-catenin pathway. J Biol Chem 2015;290:28540-58.

94. Kong X, Zhong M, Su X, Qin Q, Su H, Wan H, et al. Tetra- methylpyrazine promotes migration of neural precursor cells via activating the phosphatidylinositol 3-kinase pathway. Mol Neurobiol 2016;53:6526-39.

95. Bokara KK, Kim JH, Kim JY, Lee JE. Transfection of arginine decarboxylase gene increases the neuronal differentiation of neural progenitor cells. Stem Cell Res 2016;17:25665.

96. Jin K, Xie L, Mao X, Greenberg MB, Moore A, Peng B, et al. Effect of human neural precursor cell transplantation on endogenous neurogenesis after focal cerebral ischemia in the rat. Brain Res 2011;1374:56-62.

97. Mine Y, Tatarishvili J, Oki K, Monni E, Kokaia Z, Lindvall O. Grafted human neural stem cells enhance several steps of endogenous neurogenesis and improve behavioral recovery after middle cerebral artery occlusion in rats. Neurobiol Dis 2013;52:191-203.

98. Zhang P, Li J, Liu Y, Chen X, Lu H, Kang Q, et al. Human embryonic neural stem cell transplantation increases subventricular zone cell proliferation and promotes peri-infarct angiogenesis after focal cerebral ischemia. Neuropathology 2011;31:384-91.

99. Cho YS, Ko IG, Kim CJ, Kim KH. A novel intracerebral hemorrhage-induced rat model of neurogenic voiding dysfunction: Analysis of lower urinary tract function. Mol Med Rep 2015;12:2563-9.

100. Miyazato M, Kitta T, Kaiho Y, Oshiro T, Saito S, Chancellor $\mathrm{MB}$, et al. Effects of duloxetine on urethral continence reflex and bladder activity in rats with cerebral infarction. J Urol 2015;194:842-7. 